\title{
Article \\ Evolutionary Game Analysis of Responding to the EU's Carbon Border Adjustment Mechanism
}

\author{
Tao Huang, Zhixin Liu and Tian Zhao *
}

Citation: Huang, T.; Liu, Z.; Zhao, T. Evolutionary Game Analysis of Responding to the EU's Carbon Border Adjustment Mechanism. Energies 2022, 15, 427. https:// doi.org/10.3390/en15020427

Academic Editor: T M Indra Mahlia

Received: 4 December 2021

Accepted: 5 January 2022

Published: 7 January 2022

Publisher's Note: MDPI stays neutral with regard to jurisdictional claims in published maps and institutional affiliations.

Copyright: (C) 2022 by the authors. Licensee MDPI, Basel, Switzerland. This article is an open access article distributed under the terms and conditions of the Creative Commons Attribution (CC BY) license (https:// creativecommons.org/licenses/by/ $4.0 /)$.

\author{
School of Economics and Management, Beihang University, 37 Xueyuan Road, Beijing 100191, China; \\ buaaht@buaa.edu.cn (T.H.); liuzhixin@buaa.edu.cn (Z.L.) \\ * Correspondence: klosealan@buaa.edu.cn
}

\begin{abstract}
The European Union (EU) views the carbon border adjustment mechanism (CBAM) as a measure to tackle carbon leakage, which will have a profound impact on non-EU countries' exports. Policymakers are faced with the question of how to deal with the CBAM. In contrast to previous studies, we explore the effects of the CBAM on non-EU countries from a dynamic game perspective. This study analyzed the potential effects of the CBAM on China and found that the government and export companies are the two main stakeholders. We found that they can both choose whether to respond actively or passively. Based on their interactive relationship, we adopted an evolutionary game to model the nexus between the government and export companies. We analyzed the evolutionary stable state of each stakeholder and the whole game with the replicator dynamic equation system. To make the system evolve to the optimal state where the government reacts actively and export companies implement low-carbon production, we provide a policy mechanism for how to set key parameters' values. We used numerical simulation to verify the policy design and to conduct sensitivity analyses of the key parameters. Our results show that, when two stakeholders positively react to the CBAM, it is necessary to increase their profits and to reduce their costs. Therefore, some suggestions are proposed, including optimizing the trade structure, strengthening cooperation with the EU, improving the current carbon market, and adopting carbon tax.
\end{abstract}

Keywords: carbon border adjustment mechanism (CBAM); evolutionary game; government; export companies; China

\section{Introduction}

The European Union (EU) announced the carbon border adjustment mechanism (CBAM) in 2021 [1]. Its purpose is to levy taxes on imported goods from countries with relatively loose carbon emission restrictions. The EU proposed a specific plan for the CBAM and plans for it to take effect in five years. The transition period of this "carbon border tax" is from 2023 to 2025. During this period, importers need to monitor and report on the carbon emissions of related products. The EU CBAM legislation shows that industries such as electricity, steel, cement, aluminum, and fertilizer have become the first batch of sectors to be included in the CBAM. In the future, the EU will assess the industry coverage and gradually expand to other industries covered by the EU carbon market. The main reasons for the EU to promote the CBAM is to prevent "carbon leakage". This is to prevent local EU companies from migrating to avoid strict carbon emission reduction policies, thereby creating a level playing field and exploring a path to a global carbon price [2] Indeed, the emissions embedded in the goods and services imported to the EU have been increasing and currently represent 20 percent of the EU's domestic $\mathrm{CO}_{2}$ emissions [3]. In short, the CBAM compensates for differences in carbon prices between domestic and imported products.

However, the implementation of the CBAM will exert significant impact on non-EU countries, especially developing countries [4-6]. Some trade partners of the EU, especially 
emerging economies, expressed concerns on the potential impact of the CBAM on their exports and competitiveness [7]. The United Nations Conference on Trade and Development (UNCTAD) issued a warning that the CBAM may change the trade model, which is beneficial to countries with high resource efficiency and low carbon emissions from industrial production and is harmful to the exports of developing countries [8]. Take China for example. China is a major producer of EU imports, and the impact of the implementation of the CBAM on China-EU trade cannot be ignored. As the EU steadily advances the CBAM legislative process, although the final implementation is still uncertain, green international trade barriers will become a long-term issue [9]. Therefore, China should plan ahead and make countermeasures in advance. China has already proposed to achieve its carbon peak by 2030 and carbon neutrality by 2060 and launched the world's largest carbon trading national market in July 2021 [10]. The EU emphasizes that if non-EU countries take climate response measures equivalent to those of the EU, they will be entitled to exemption from the CBAM [11]. However, currently only the electrical sector is included in the carbon market, and there is little electricity trade between China and the EU. Therefore, most export companies in China are subject to huge impact due to the CBAM. The CBAM raises questions of how non-EU countries and exporters respond to this carbon tariff policy [9].

In the context of the CBAM, the government and export companies from non-EU countries are two salient actors that will decide how to react to potential impact caused by the implementation of the CBAM from the perspective of non-EU countries [12,13]. Based on the literature on the interplay between the government and companies related to environmental regulation and low-carbon technology diffusion [14-18], it can be summarized that the government hopes companies can alleviate carbon emissions and explores whether to implement active regulation or passive regulation; companies will also assess the potential benefits of low-carbon transition mode and then decide whether to implement low-carbon production. Both actors interact to maximize respective profit under specific conditions. Accordingly, it is reasonable that the government and export companies are the stakeholders in the context of the CBAM [12,13]. Given their interactive relationship, game theory is regarded as a suitable approach to study their mutual strategic decision-making and how to obtain the optimal equilibrium result [19]. However, no study has analyzed the nexus between the government and export companies in a game from the angle of non-EU countries.

The objective of this study was to examine how the EU CBAM might impact non-EU countries as global exporters and how they respond. Specifically, we take the case of China as an example which is the world's largest carbon emitter and is potentially affected by the CBAM [20-23]. By expounding the nexus between Chinese government and export companies, we study how both actors respond to the CBAM in order to maximize their own payoff while considering low-carbon development. This paper has two main contributions to the current literature: (i) This is the first study to focus on the reaction of a non-EU country to the CBAM. (ii) We are the first to use a dynamic game framework to provide a new angle for actors' mutual strategic decision-making. The aim of this study was to answer the following question: "How should policy-makers promote cooperation between the government and export companies to actively respond to the CBAM together?". In conclusion, we provide a policy mechanism for cooperation between the government and export companies to actively respond to the CBAM. Moreover, we provide policy recommendations to promote the smooth operation of this policy mechanism. This paper is expected to provide new insights into how to respond to the CBAM for other affected countries.

The remainder of this paper is organized as follows. Section 2 presents the literature review on the CBAM, the research gap, and the originality of this paper. Section 3 introduces the potential impact of the CBAM on China and identifies main actors in the game. Section 4 describes the evolutionary game model used for the analysis, the parameters in the model, and game payoff matrix. Section 5 elaborates the results of evolutionary stable strategy and numerical simulation. Section 6 is the discussion based on results. Section 7 presents our conclusions and policy implications. 


\section{Literature Review}

There are several strands of literature on the CBAM. Cosbey et al. [24] reviewed the literature on the CBAM from economic and legal perspectives, summarizing implications for the design and implementation of the CBAM and illustrating a research pivot. Yu et al. [25] reviewed the literature on policy instruments for addressing carbon leakage and concluded that the CBAM is the most discussed tool. Some research shows that the CBAM contributes to the reduction in carbon leakage [26-29], with its welfare impact being typically small and slightly negative at the world level [30]. Rocchi et al. [31] give a CBAM design on the grounds of avoiding emissions at a product level. Droege [32] argues that the CBAM can close the gap between produced and consumed carbon in a territory. Zhang et al. [33] use a computable general equilibrium (CGE) model to show that the CBAM is more useful for mitigating carbon leakage than other policies in the U.S. Dissou and Eyland [34] apply a CGE model to find that the CBAM could enhance the competitiveness of domestic producers in relation to their foreign counterparts. Mörsdorf [35] also uses the CGE model to assess the effects of various versions of the CBAM on the output and revenue of EU energy-intensive industries and compares CBAM with the present free allocation policy. Jakob [36] argues that if major emitters worldwide apply the CBAM, competitiveness in international trade will be eliminated, which will incentivize other economies to adopt low-carbon strategies. Gerbeti [37] illustrates that the CBAM is an effective way to reduce emissions while maintaining the EU's industrial competitiveness. Thube et al. [38] suggest that the CBAM can incentivize countries that have not implemented carbon pricing policies yet to join the climate club. Fischer and Fox [39] compare four likely policy mechanisms for carbon leakage: a border carbon tariff on imports, a border rebate for exports, full border adjustment and domestic output-based rebating, with the result showing that full border adjustment is most effective. Acar et al. [40] estimate negative impacts of the CBAM on the Turkish economy by means of the input-output method and multi-sector applied general equilibrium model. The results show that the cement and power industries will be primarily influenced. Therefore, we formulated the following hypothesis:

Hypothesis 1 (H1). The implementation of the CBAM is effective against carbon leakage with small welfare loss.

However, Winchester et al. [41] assess the effect of the CBAM proposed in the American Clean Energy and Security Act of 2009 and find that the CBAM is a costly measure to alleviate carbon leakage accompanied by huge welfare loss but may be an effectively coercive strategy. Likewise, Li and Zhang [22] apply China as an example to find that the CBAM would be an inefficient tool to alleviate emissions compared with carbon taxes. Bao et al. [42] find that the widespread use of low-carbon fuels and technologies will be more effective than CBAM. Lin and $\mathrm{Li}$ [21] study the likely effects of the CBAM on various regions of China to show that there are apparent differences among different regions in terms of their respective reactions to the CBAM. They also believe that the CBAM may not be an effective policy to impede carbon leakage. Li et al. [23] compare the impact of the CBAM on typical emerging countries and explore different policy designs to counteract the negative impacts on China's output. Kuik and Hofkes [43] illustrate that from an environmental point of view the CBAM is not very effective but would still be justified when taking into account sectoral competitiveness. Holmes et al. [44] conclude that the case for the CBAM based on carbon leakage and hence lost competitiveness is weak. Sakai and Barrett [45] find that the CBAM is not the ideal policy mechanism for carbon leakage. Schinko et al. [46] argue that the CBAM would harm the switch to low-carbon production technologies. The CBAM can be regarded as a transitional tool for maintaining domestic competitiveness and reducing carbon leakage until low-carbon technologies become available at a large scale. Weitzel et al. [47] confirm that the CBAM has limited effects on mitigating carbon leakage. Banks and Fitzgerald [48] argue that the implementation of the CBAM will cause protectionism and potential retaliatory policies and cannot reduce emissions effectively. 
They suggest an alternative policy called cooperative sectoral tariff reduction (CSTR) and believe CSTR can offer more incentives to alleviate carbon leakage. Lim et al. [6] study the impact of the CBAM policy on exporters through the dynamic CGE approach. They explore the probable legal issues and potential danger of the CBAM and estimate its hidden global cost and find that the CBAM will harm the world trade market, especially in emerging economies. Eicke et al. [49] show that relative risks related to the EU's CBAM are unequally distributed worldwide, while Southeastern European and African countries will encounter relatively high risks. Therefore, we propose the following hypothesis:

Hypothesis 2 (H2). The implementation of the CBAM is not the optimal tool for reducing carbon leakage accompanied by the welfare loss.

Sanctuary [50] argues that the CBAM has the possibility to both help and harm carbon reduction efforts. Additionally, various stakeholders involved in the CBAM, such as EU and non-EU exporting countries, importers, and exporters interact with each other to maximize their own profits [51,52]. Mehling et al. [53] propose a CBAM design in order to level legal risks, environmental efficacy, and political feasibility. Monjon and Quirion [54] contrast different designs of the CBAM and find that the incorporation of imports and exports would decrease total emissions more than only the incorporation of imports. Therefore, we hypothesized that:

Hypothesis 3 (H3). There is no scholarly consensus on how the CBAM is defined or the potential effects of the CBAM on the stakeholders.

Helm and Schmidt [55] apply a cooperative game model to demonstrate that the CBAM would be useful for guiding countries to participation in a climate coalition. Hecht and Peters $[12,13]$ use two-stage and three-stage games, respectively, to study the two countries' competition in the context of the CBAM. Similarly, Anouliès [56] finds that the CBAM is useful to countries' participation in the international carbon agreement by using a Cournot game to model a two-country two-firm reciprocal market. Irfanoglu et al. [57] combine a four-stage game with a CGE model to demonstrate that the CBAM can impede the free-rider problem and prompt the U.S. to adopt a carbon tax. Eyland and Zaccour [58] use both noncooperative and cooperative games to explain how to set the value of the CBAM to maximize total social welfare. However, the game models used in these studies are all classic static games which regard actors as having complete rationality.

The evolutionary game relaxes the hypothesis of complete rationality and extends the classic game to present the evolution of populations and investigate which strategy will eventually be chosen by the majority of populations [59,60]. Scholars have used evolutionary games between governments and enterprises in illuminating research in the field of low-carbon development. Chen and $\mathrm{Hu}$ [15] apply the evolutionary game to explore the nexus between manufacturers and government considering carbon taxes and subsidies. They study how various strategies of government and population of manufacturers could be evolved. Wu et al. [61] use a complex network model coupled with an evolutionary game between the government and enterprise environment and study the impact of governmental incentives on enterprises. Fan et al. [62] build evolutionary game models in the case with and without government intervention between the government and enterprises and explore the ideal regulation strategy and the corresponding optimum supervision probability. Mahmoudi and Rasti-Barzoki [63] study the influence of government policies on enterprises' behavior and carbon emissions through an evolutionary game. Long et al. [64] find that consumers have an important influence on the strategy evolution of government and enterprises in the take-out waste recycling industry chain.

Therefore, we hypothesized that: 
Hypothesis 4 (H4). Game theory is suitable to analyze actors' mutual interest conflicts and interactive nexus. Further, the evolutionary game can provide a dynamic insight into the evolution strategy of the actors in the context of the CBAM.

We can see that although there is still no consensus on the effect of the CBAM, the actors who are likely to be affected by the CBAM need to prepare for its potential impact. In sum, however, the existing literature has two knowledge gaps. First, game theory is a useful tool to study this issue and has been used, but it only uses the static game to study the issues of the CBAM in previous studies. Second, the studies of stakeholders so far have only used the perspective of import countries and export countries. This study's novelty consists of two aspects: (i) To the best of our knowledge, the present study is the first to use a dynamic game called the evolutionary game to analyze the interplay between actors in the context of the CBAM. The evolutionary game can overcome the drawbacks of a static game [65]. (ii) No other study has yet analyzed the interplay between the government and export companies of non-EU exporting countries. We take the Chinese government and export companies as examples to provide a new perspective on the matter.

\section{Problem Description}

\subsection{The Effect of the CBAM on China}

Countries that export large amounts of carbon-intensive products to countries that have established carbon border taxes are most affected by the CBAM. China's export products have high carbon intensity and a high degree of export dependence. The EU has been China's largest trading partner for a long time. At the same time, the U.S., Japan, and South Korea were China's top trading partners in 2020. China's export trade is dependent on developed countries' markets. The status quo of China's trade determines that the CBAM will have a certain impact on export trade.

From an industry perspective, energy-intensive industries will be most affected by the CBAM. Since there is no electricity trade between China and the EU, and the export of fertilizer and cement is small, the main affected companies will be in the steel and aluminum sectors. The challenges for these companies include increased costs and decreased competitiveness. Because China's aluminum emissions mainly come from indirect emissions from electricity, if the CBAM includes indirect emissions it will significantly increase the cost of Chinese aluminum products exported to the EU. Meanwhile, the EU carbon market also covers other industries such as papermaking, chemical industry, and oil refining. It is possible that these industries will also be included in the future CBAM.

On the other hand, the CBAM will have an impact on China's overall export situation. The direct export of Chinese steel and aluminum to the EU only accounts for 3\% of China's total export to the EU. Nearly $60 \%$ of China's exports are mechanical and electrical products, which are downstream from the steel and aluminum industry. Even if the CBAM only covers direct exports from the steel and aluminum industries, the resulting increase in steel and aluminum costs will also have an indirect impact on related industrial chains. Furthermore, the CBAM will not only affect China but also Russia, Turkey, and other countries. If China's relevant industries take extensive low-carbon transformation measures to ensure that similar products contain fewer carbon emissions, it will improve China's export competitiveness.

\subsection{Main Actors}

The implementation of the CBAM will increase China's export costs and affect China's trade competitiveness. Take the steel industry for example, which will be the most affected Chinese sector under the CBAM. The steel industry has the largest carbon emissions in the field of energy terminal consumption. In order to promote the transformation of steel companies to cleaner production to reduce emissions and to react to the CABM policy, steel companies need to invest in low-carbon technologies and should be included in the carbon market. 
However, incorporating a new industry into the carbon market and investing in lowcarbon equipment require large human, financial, and material inputs. This is because the improvement of the carbon market not only needs to update the overall system but also includes support from enterprises to collect substantial in-house emissions data. In addition, the implementation of the CBAM is still uncertain, and the impact of the CBAM on total EU imports from China and other major trade partners may be very small [66]. These factors will cause the government and export companies to choose to react passively to the CBAM. For example, China has cancelled export tax rebates for 23 steel products including rails in August 2021. This measure will reduce steel exports and give priority to meeting domestic demand.

On the other hand, if the government takes the opportunity to address the trade barriers created by the CBAM and actively improve the carbon market and other carbon pricing policies, it will receive huge social benefits. The CBAM will promote the adjustment of energy structure and the optimization of trade structure. China will also have the opportunity to take the initiative in the international carbon market. For export companies, in order to minimize the negative impact of the CBAM and increase their competitiveness compared to others, they will increase their resource utilization rate and optimize industrial structure. At the same time, companies will actively develop low-carbon technologies and look for new alternative energy sources.

Accordingly, the government can decide whether to react to the CBAM actively or passively. Export companies can choose whether to adopt traditional high-carbon production or innovative low-carbon production. Both government and export enterprises are bounded by rationality. Stakeholders can learn from each other to make adjustments.

\section{Methodology}

\subsection{Parameter Assignment and Payoff Matrix}

Based on above problem description, we can see the conflict of interests on response to the CBAM between the governments and export companies in China. Both actors consider their respective situation and seek to maximize their own interests through interplay. Game theory is applied to study interplay between various actors in the process of decision-making [67]. Further, stakeholders in real life are interlinked in the evolution process of games where they decide strategies dynamically. Evolutionary game theory has been proved an effective method which can offer dynamic insights into the interplay between stakeholders [68]. Therefore, evolutionary game theory is suitable for exploring the authentic interaction of the game [69]. Moreover, evolutionary game theory relaxes the assumption in the static game that all players have overall rationality and view the game course as a dynamic process to be consistent with real life [70]. Some studies have used evolutionary game theory to study interactions between actors in the field of low-carbon development to lay a solid foundation for this study $[14,15,71]$. Therefore, in this study, we used evolutionary game theory to study the interplay between the government and export companies in the context of the CBAM.

According to the aforementioned description of main actors, relevant parameters of the game model can be defined. The government can decide whether to react to the CBAM actively or passively, with the initial probability being $x$ and $1-x$, respectively. Export companies can choose whether to adopt high-carbon production or low-carbon production, with the initial probability being $y$ and $1-y$, respectively. Under the condition that the government actively responds to the CBAM, if the export companies implement low-carbon production, the government will gain long-term economic, social, and environmental benefits from $G_{r}$, such as approval and recognition from the EU. The reactive measures include incorporation of the steel and aluminum industries that are heavily affected by the CBAM into the carbon market and trying to implement carbon tax policies. The implementation cost of these measures is $G_{c}$. The government will provide export rebates $E_{r}$ and financial subsidies $S_{g}$ for export companies that decide to adopt low-carbon production. When the government actively responds and finds that export companies still stick to high- 
carbon production, export companies are subject to penalties $P_{g}$ from the government, such as purchasing additional carbon allowance, paying the carbon tax, or fines. Meanwhile, if export companies choose high-carbon production, the government is responsible for the potential loss $G_{l}$. For export companies, if they continue to adopt high-carbon production, the profit is $C_{h}$. If they decide to adopt low-carbon production, they will obtain additional profit $P_{l}$ such as sales of spare carbon allowance or sale increases due to EU admission, along with extra costs $C_{l}$ due to purchasing low-carbon equipment.

The meanings of the parameters and the payoff matrix are shown in Tables 1 and 2.

Table 1. Parameter definitions of the evolutionary game model.

\begin{tabular}{|c|c|c|}
\hline Symbols & Stakeholders & Descriptions \\
\hline$G_{r}$ & \multirow{7}{*}{ Government } & $\begin{array}{l}\text { Political benefits because of the active reaction to } \\
\text { the CBAM. }\end{array}$ \\
\hline$G_{c}$ & & The expenditure of active reaction to the CBAM. \\
\hline$S_{g}$ & & Financial incentives such as subsidies. \\
\hline$P_{g}$ & & $\begin{array}{l}\text { The penalty for export companies with } \\
\text { high-carbon production. }\end{array}$ \\
\hline$E_{r}$ & & Export rebates. \\
\hline$G_{l}$ & & The loss of excessive carbon emissions. \\
\hline$x$ & & $\begin{array}{l}\text { The initial probability that the government chooses an } \\
\text { active reaction to the CBAM. }\end{array}$ \\
\hline $1-x$ & \multirow{6}{*}{ Export companies } & $\begin{array}{l}\text { The initial probability that the government chooses a } \\
\text { negative reaction to the CBAM. }\end{array}$ \\
\hline$C_{h}$ & & Return if adopting the high-carbon production. \\
\hline$P_{l}$ & & Low-carbon profit. \\
\hline$C_{l}$ & & Extra cost for low-carbon production. \\
\hline$y$ & & $\begin{array}{c}\text { The initial probability that the export companies choose } \\
\text { low-carbon production. }\end{array}$ \\
\hline $1-y$ & & $\begin{array}{c}\text { The initial probability that the export companies choose } \\
\text { high-carbon production. }\end{array}$ \\
\hline
\end{tabular}

Table 2. Payoff matrix.

\begin{tabular}{cccc}
\hline & & \multicolumn{2}{c}{ Export Companies } \\
\cline { 3 - 4 } & & Low-Carbon Production & High-Carbon Production \\
\hline \multirow{3}{*}{ Government } & Active reaction & $G_{r}-G_{c}-E_{r}-S_{g}$ & $P_{g}-G_{c}-G_{l}$, \\
& Passive reaction & $C_{h}+P_{l}+E_{r}+S_{g}-C_{l}$ & $C_{h}-P_{g}$ \\
& $0, C_{h}+P_{l}-C_{l}$ & $-G_{l}, C_{h}$ \\
\hline
\end{tabular}

\subsection{Replicator Dynamic Equations}

The evolutionary game model was first proposed by Smith and Price in 1973 [72]. The actors would repeat a game by pairing randomly in the group and finally find evolutionary stable states [73]. This analytical process is analogous to the behavioral mode in practical decision-making. The core of the evolutionary game model is to investigate the strategic adjustment mechanism. When the rationality of the actors is involved, the replicator equations of biological evolution can be used to simulate their dynamic evolution trajectories [70]. Due to information asymmetry, the strategy choices of actors have mutual effects and can be affected by the results of the previous game. This determines the features of inheritance and dynamics of the game, resembling the process of population evolution.

The most widely used dynamic game mechanism is the replicator equation proposed by Taylor and Jonker [70]. When the game actor has slow learning speed and low rationality degree, the replicator equation will be suitable for the strategy adjustment in a repetitive game with random pairing of large groups. The evolutionary stable strategy is obtained when the majority of individuals in the population choose a certain strategy, the group which selects the mutation strategy cannot invade the group that contains the majority of individuals because it includes minority individuals. The replicator equation means 
a dynamic differential equation. Based on the evolutionism, if the payoff of a strategy is bigger than the average payoff, this strategy will dominate. This means the growth rate of this strategy is higher than zero. The replicator equation is shown as follows [74]:

$$
\frac{d x_{k}}{d t}=x_{k}[u(k, s)-u(s, s)], k=1,2,3, \ldots, K
$$

where $x_{k}$ means the percentage of the population choosing strategy $k, u(k, s)$ denotes the payoff choosing strategy $k, u(s, s)$ represents the average payoff, $k$ is various strategies, and $K$ is the total strategies. When $\frac{d x_{k}}{d t}$ gets the stable state, strategy $k$ is the evolutionary stable strategy. The replicator equation shows the frequency at which specific strategies change over time. We can calculate the replicator equations of each principal strategy using the payoff matrix [64]. When game players are multiple groups, the equilibrium stable solutions are the Nash equilibria of pure strategies [69]. The replicator equations are used to seek the system's stable strategy, as outlined in Section 5.

\section{Results}

\subsection{Analysis of Government's Evolutionary Stable Strategies}

Expected return for the government to respond positively $U_{g 1}$ and negatively $U_{g 2}$ and average expected return $\bar{U}_{g}$ is obtained by:

$$
\begin{gathered}
U_{g 1}=y\left(G_{r}-G_{c}-E_{r}-S_{g}\right)+(1-y)\left(P_{g}-G_{c}-G_{l}\right) \\
U_{g 2}=-(1-y) G_{l} \\
\overline{U_{g}}=x U_{g 1}+(1-x) U_{g 2}
\end{gathered}
$$

The replicator dynamics equation of the government adopting an active reaction is obtained by:

$$
F(x)=\frac{d x}{d t}=x\left(U_{g 1}-\overline{U_{g}}\right)=x(1-x)\left[y\left(G_{r}-E_{r}-S_{g}-P_{g}\right)+P_{g}-G_{c}\right]
$$

Let $F(x)$ be 0 , we obtain $x_{1}=0, x_{2}=1, y^{*}=\frac{G_{c}-P_{g}}{G_{r}-E_{r}-S_{g}-P_{g}}$.

(1) If $y=y^{*}, F(x) \equiv 0$. This shows that when the proportion of export enterprises implementing low-carbon production strategies is exactly $y^{*}$, all the strategies adopted by the government will be in a stable state, and the dynamic evolution phase diagram is shown in Figure 1a. In other words, all points on the $x$-axis can be stable strategic points. The government expects the same payoff when it chooses "positive reaction" and "negative reaction". The government's final choice is made under the influence of various conditions.

(2) If $y \neq y^{*}$, according to the requirements of the evolutionary stability strategy [75], $x$ that satisfies $F(x)=0$ and $F^{\prime}(x)<0$ is the evolutionary stable state point of the government. The derivative of $F(x)$ is:

$$
F^{\prime}(x)=(1-2 x)\left[y\left(G_{r}-E_{r}-S_{g}-P_{g}\right)+P_{g}-G_{c}\right]
$$

When $G_{c}>P_{g}, y<y^{*}$, we obtain $F^{\prime}(1)>0, F^{\prime}(0)<0$. Therefore, $x=0$ is an evolutionary stable state; that is, the government will consider a negative reaction. This shows that when the initial probability of export companies choosing low-carbon production is less than a certain value, and the government's regulatory costs are greater than the loss for companies that do not conduct low-carbon production, the government tends to choose a negative reaction to the CBAM. The dynamic diagram is shown in Figure $1 \mathrm{~b}$.

(3) When $G_{c}>P_{g}, y>y^{*}$, we obtain $F^{\prime}(1)<0, F^{\prime}(0)>0 . x=1$ is an evolutionary stable state; that is, the government will consider a reaction to the CBAM. This shows 
that although the government's regulatory costs are greater than the loss imposed on export companies that do not engage in low-carbon production, when the initial probability of export enterprises that choose low-carbon production is greater than a certain value, the government still prefers to actively respond to the CBAM. The dynamic diagram is shown in Figure 1c.

(4) When $G_{c}<P_{g}$ and $G_{r}-E_{r}-S_{g}-P_{g}>0, y>y^{*}$ is satisfied for any $y$ [0,1]. At this time, $F^{\prime}(1)<0, F^{\prime}(0)>0$, so $x=1$ is an evolutionary stable state; that is, the government will consider actively responding to the CBAM. This is mainly because the government has collected enough fines for export enterprises that still conduct traditional energy-intensive production and the returns from active reaction to the CBAM are also large enough. Regardless of the initial willingness of export enterprises, the government will eventually implement active reaction to the CBAM. The dynamic diagram is shown in Figure 1c.

(5) When $G_{c}<P_{g}, G_{r}-E_{r}-S_{g}-P_{g}<0, y<y^{*}$, because $F^{\prime}(1)>0, F^{\prime}(0)<0, x=0$ is an evolutionarily stable status; that is, the government will consider negative reaction to the CBAM. This is because the government's penalty on export companies that do not implement low-carbon production is small, and the government's supervision of the export companies cannot bring great political benefits. When the initial probability of export companies choosing low-carbon production is less than $y^{*}$, the final evolutionary result of the government is not to actively respond to the CBAM. The dynamic diagram is shown in Figure $1 b$.

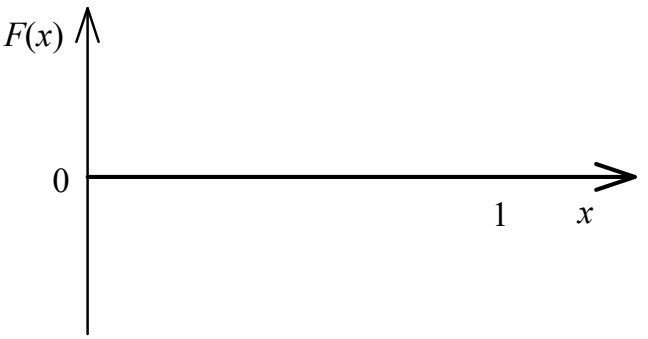

(a)

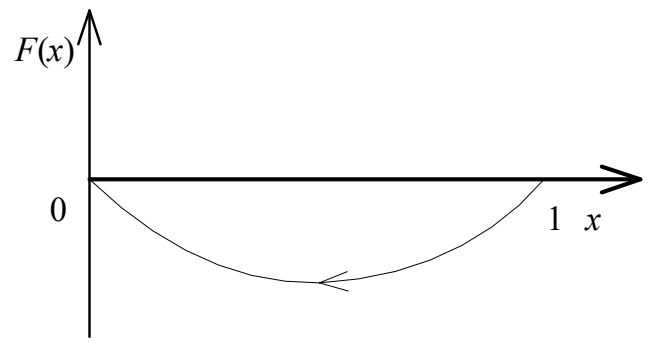

(b)

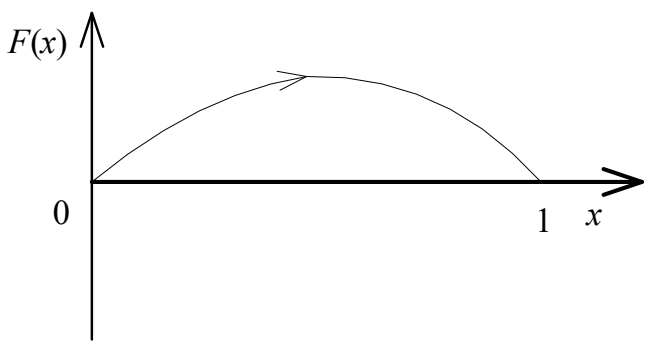

(c)

Figure 1. The dynamic evolutionary diagram of the government under various cases. (a) The dynamic diagram of governmental strategy when $y=y^{*}$. (b) The dynamic diagram of governmental strategy when $x=0$ is an evolutionary stable state. (c) The dynamic diagram of governmental strategy when $x=1$ is an evolutionary stable state.

(6) When $G_{c}<P_{g}, G_{r}-E_{r}-S_{g}-P_{g}<0, y>y^{*}$, because $F^{\prime}(1)<0, F^{\prime}(0)>0, x=1$ is an evolutionary stable state; that is, the government will consider active reaction to the CBAM. The government's penalty on export companies that retain traditional production modes is small, and the government's reaction to the CBAM cannot bring great political performance benefits. When export companies choose low-carbon pro- 
duction with the initial probability being greater than $y^{*}$, the final evolutionary result of the government is active reaction. The dynamic diagram is shown in Figure 1c.

\subsection{Analysis of Export Companies' Evolutionary Stable Strategies}

Expected return for the export enterprise to implement low-carbon production $U_{e 1}$ and traditional production $U_{e 2}$ and average expected return $\bar{U}_{e}$ is obtained by:

$$
\begin{gathered}
U_{e 1}=x\left(C_{h}+P_{l}+E_{r}+S_{g}-C_{l}\right)+(1-x)\left(C_{h}+P_{l}-C_{l}\right) \\
U_{e 2}=x\left(C_{h}-P_{g}\right)+(1-x) C_{h} \\
\overline{U_{e}}=y U_{e 1}+(1-y) U_{e 2}
\end{gathered}
$$

The replicator dynamics equation of the export enterprise adopting low-carbon production is obtained by:

$$
F(y)=\frac{d y}{d t}=y\left(U_{e 1}-\overline{U_{e}}\right)=y(1-y)\left[x\left(E_{r}+S_{g}+P_{g}\right)+P_{l}-C_{l}\right]
$$

Let $F(y)$ be 0 ; we obtain $y_{1}=0, y_{2}=1, x^{*}=\frac{C_{l}-P_{l}}{E_{r}+S_{g}+P_{g}}$.

(7) If $x=x^{*}$, we obtain $F(y) \equiv 0$. This shows that when the initial probability of the government choosing an active reaction is exactly $x^{*}$, all strategies adopted by export companies will be in a stable state. All points on the $y$-axis can be stable strategy points; that is, export companies are facing the case that the expected payoff for "low-carbon production" and "high-carbon production" are the same, and the final choice will be made under various conditions. The dynamic diagram is shown in Figure 2a.

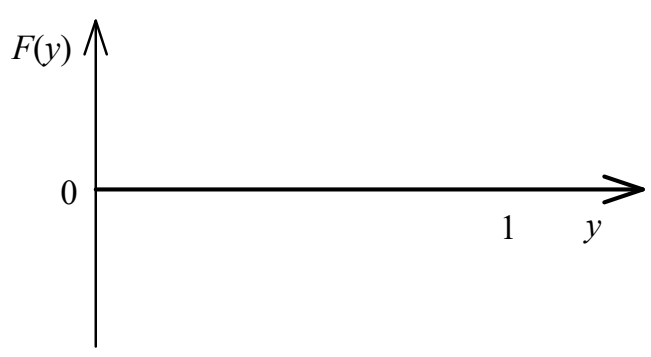

(a)

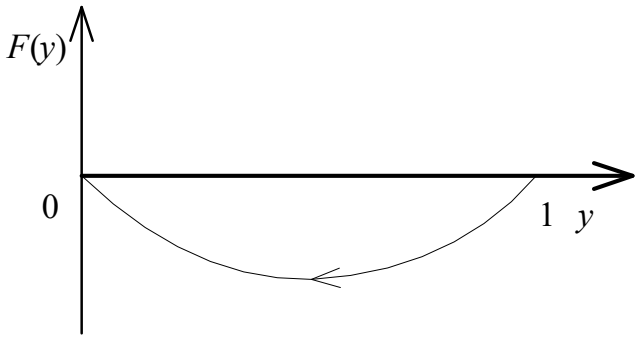

(b)

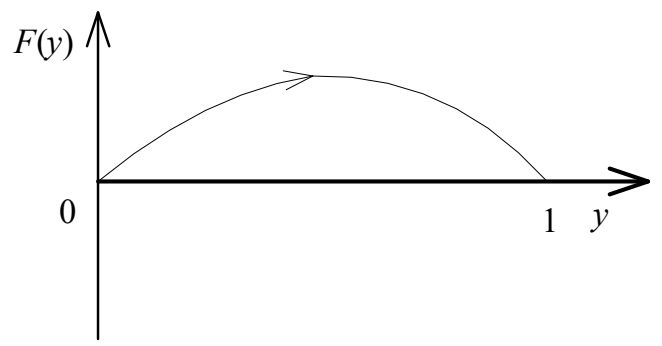

(c)

Figure 2. The dynamic evolutionary diagram of export enterprises under various cases. (a) The dynamic diagram of company strategy when $x=x^{*}$. (b) The dynamic diagram of company strategy when $y=0$ is an evolutionary stable state. (c) The dynamic diagram of governmental strategy when $y=1$ is an evolutionary stable state. 
(8) If $x \neq x^{*}, y$ satisfies $F(y)=0$ and $F^{\prime}(y)<0$ is the evolutionary stable state point of the export enterprise. The derivative of $F(y)$ is:

$$
F^{\prime}(y)=(1-2 y)\left[x\left(E_{r}+S_{g}+P_{g}\right)+P_{l}-C_{l}\right]
$$

When $x<x^{*}$, because $F^{\prime}(1)>0, F^{\prime}(0)<0, y=0$ is an evolutionary stable state; that is, export companies will choose to maintain high-carbon production. This shows that when the government's choice of active reaction is less than $x^{*}$, the behavior of export companies still implementing high-carbon production is unlikely to be regulated, which provides them with convenient conditions for seeking short-term benefits. The dynamic diagram is shown in Figure $2 b$.

(9) When $x>x^{*}$, because $F^{\prime}(1)<0, F^{\prime}(0)>0, y=1$ is an evolutionary stable state; that is, export companies will consider adopting low-carbon production. This is because when the initial probability of the government choosing an active reaction to the CBAM is greater than $x^{*}$, export companies are regulated easily, which will cause high losses to the enterprise. Therefore, export companies will be more inclined to implement low-carbon production. The dynamic diagram is shown in Figure 2c.

\subsection{Systematic Stability Analyses}

The entire game replicator dynamic system is composed of Equations (5) and (10). This system has five equilibrium points, i.e., $A(0,0), B(0,1), C(1,0), D(1,1)$, and $E\left(x^{*}, y^{*}\right)$. The Jacobian matrix $(J)$ is shown as Equations (12) and (13). It is used to analyze the stability of the evolutionary game system by means of examining the symbols of its determinants and traces [76]. In the specific determination method, the point represents the evolutionary stable strategy of the game system when its symbol of the determinant is positive and symbol of the trace is negative.

$$
\begin{gathered}
J=\left[\begin{array}{ll}
\frac{\partial(d x / d t)}{\partial x} & \frac{\partial(d x / d t)}{\partial y} \\
\frac{\partial(d y / d t)}{\partial x} & \frac{\partial(d y / d t)}{\partial y}
\end{array}\right]=\left[\begin{array}{cc}
a_{11} & a_{12} \\
a_{21} & a_{22}
\end{array}\right] \\
\left\{\begin{array}{c}
a_{11}=(1-2 x)\left[y\left(G_{r}-E_{r}-S_{g}-P_{g}\right)+P_{g}-G_{c}\right] \\
a_{12}=x(1-x)\left(G_{r}-E_{r}-S_{g}-P_{g}\right) \\
a_{21}=y(1-y)\left(E_{r}+S_{g}+P_{g}\right) \\
a_{22}=(1-2 y)\left[x\left(E_{r}+S_{g}+P_{g}\right)+P_{l}-C_{l}\right]
\end{array}\right.
\end{gathered}
$$

The determinants and traces of the Jacobian matrix at each equilibrium point are shown in Table 3 and Equation (14).

$$
\left\{\begin{array}{c}
b_{11}=\left(P_{g}-G_{c}\right)\left(P_{l}-C_{l}\right) \\
b_{12}=P_{g}-G_{c}+P_{l}-C_{l} \\
b_{21}=\left(G_{r}-E_{r}-S_{g}-G_{c}\right)\left(P_{l}-C_{l}\right) \\
b_{22}=G_{r}-E_{r}-S_{g}-G_{c}-P_{l}+C_{l} \\
b_{31}=\left(G_{c}-P_{g}\right)\left(E_{r}+S_{g}+P_{g}+P_{l}-C_{l}\right) \\
b_{32}=E_{r}+S_{g}+G_{c}+P_{l}-C_{l} \\
b_{41}=\left(G_{r}-E_{r}-S_{g}-G_{c}\right)\left(E_{r}+S_{g}+P_{g}+P_{l}-C_{l}\right) \\
b_{42}=G_{c}-G_{r}-P_{g}-P_{l}+C_{l} \\
b_{51}=\frac{\left(P_{g}-G_{c}\right)\left(C_{l}-P_{l}\right)\left(G_{r}-G_{c}-S_{g}-E_{r}\right)\left(E_{r}+S_{g}+P_{g}+P_{l}-C_{l}\right)}{\left(E_{r}+S_{g}+P_{g}\right)\left(G_{r}-E_{r}-S_{g}-P_{g}\right)} \\
b_{52}=0
\end{array}\right.
$$


Table 3. Results of determinants and traces of Jacobian matrix at each equilibrium point.

\begin{tabular}{ccc}
\hline Equilibrium Points & Determinants & Traces \\
\hline$A(0,0)$ & $b_{11}$ & $b_{12}$ \\
$B(0,1)$ & $b_{21}$ & $b_{22}$ \\
$C(1,0)$ & $b_{31}$ & $b_{32}$ \\
$D(1,1)$ & $b_{41}$ & $b_{42}$ \\
$E\left(x^{*}, y^{*}\right)$ & $b_{51}$ & $b_{52}$ \\
\hline
\end{tabular}

Of the five equilibrium points, only $D(1,1)$ is the ideal outcome because it indicates the state of cooperation where the government actively responds to the CBAM and implements comprehensive carbon pricing policy to avoid carbon leakage and export companies positively putting the low-carbon mode into practice. The condition is that $\left(G_{r}-E_{r}-S_{g}-G_{c}\right)\left(E_{r}+S_{g}+P_{g}+P_{l}-C_{l}\right)>0$ and $G_{c}-G_{r}-P_{g}-P_{l}+C_{l}<0$. To simplify the analysis, we hypothesized that the additional cost of choosing low-carbon production for a company is less than the sum of the additional low-carbon benefits it receives plus governmental subsidies, export tax rebates, and penalties. That is, $E_{r}+S_{g}+P_{g}+P_{l}-C_{l}>0$. Therefore, in order to obtain a policy design that makes the system evolve to $D(1,1)$, the conditions that the parameters need to meet are shown in Equation (15).

$$
\left\{\begin{array}{c}
G_{r}-E_{r}-S_{g}-G_{c}>0 \\
G_{c}-G_{r}-P_{g}-P_{l}+C_{l}<0 \\
E_{r}+S_{g}+P_{g}+P_{l}-C_{l}>0
\end{array}\right.
$$

Thus, the research hypothesis $\mathbf{H 1}$ is supported because we can indeed design a policy mechanism for export countries and companies to mitigate carbon leakage and with an ideal social outcome. Herein, we focus on how to promote the active cooperation between the government and export companies. However, if the parameter values meet the condition that $b_{11}>0$ and $b_{12}<0$, the point $A(0,0)$ will be the evolutionary stable strategy, supporting hypothesis $\mathbf{H} 2$ and meaning that both the government and export companies select to respond to the CBAM passively. Therefore, for export countries and companies, the potential effects of the CBAM on the stakeholders are not certain because the setting of parameter values is uncertain. This supports Hypothesis H3. However, based on the evolutionary game model, we can indeed analyze the nexus between both actors and provide effective advice on how to set values of parameters to promote the evolution of the game to the ideal state. Hypothesis $\mathbf{H 4}$ is supported accordingly.

\subsection{Numerical Simulation}

In order to verify the game results, we conducted numerical simulations. We set the values that meet Equation (15). Specifically, we let $G_{r}=18, E_{r}=3, S_{g}=4, G_{c}=5, P_{g}=5$, $P_{l}=8, C_{l}=10$. Then, we conducted the numerical simulation based on Equations (5) and (10). The diagram is shown in Figure 3. The $x$-axis means the initial probability that the government chooses an active reaction to the CBAM, and the $y$-axis means that the initial probability that the export companies choose low-carbon production (please see descriptions in Table 1). The curves in different colors denote the evolution trajectories of $x$ and $y$ with various initial values. In Figure 3, the initial values of $x$ and $y$ are set from 0.1 to 0.9 at intervals of 0.1 . We see that the game evolves to the $D(1,1)$. This means the solution of the game is correct.

Next, we conducted sensitivity analyses of these key parameters. Values of each parameter float up or down due to one of the bases of the initial value. The initial probability of each actor is set to 0.5 to reflect the strategic neutrality. The evolutionary diagrams of each parameter $\left(G_{r}, E_{r}, S_{g}, G_{C}, P_{g}, P_{l}, C_{l}\right)$ are shown in Figures 4-10. 


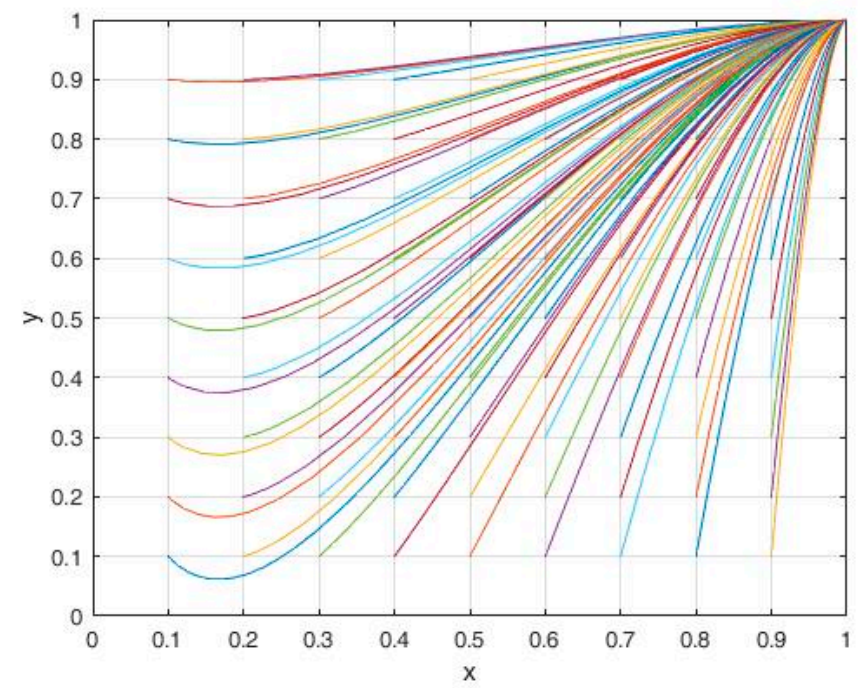

Figure 3. The dynamic evolutionary diagram of the system.
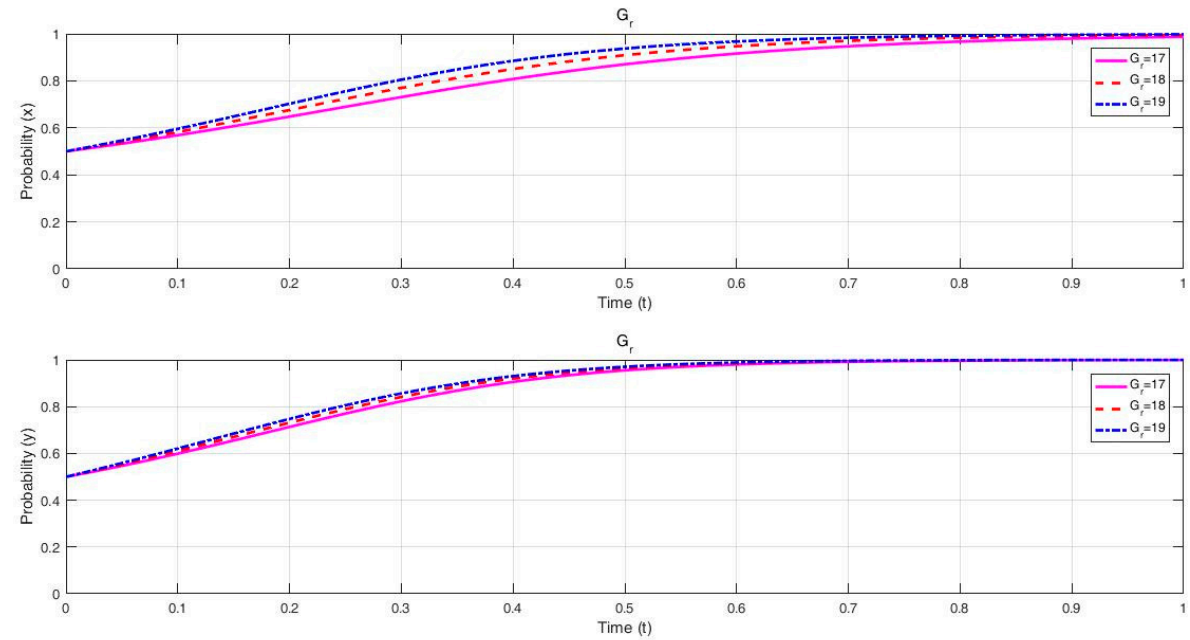

Figure 4. The impact of $G_{r}$ on the game.
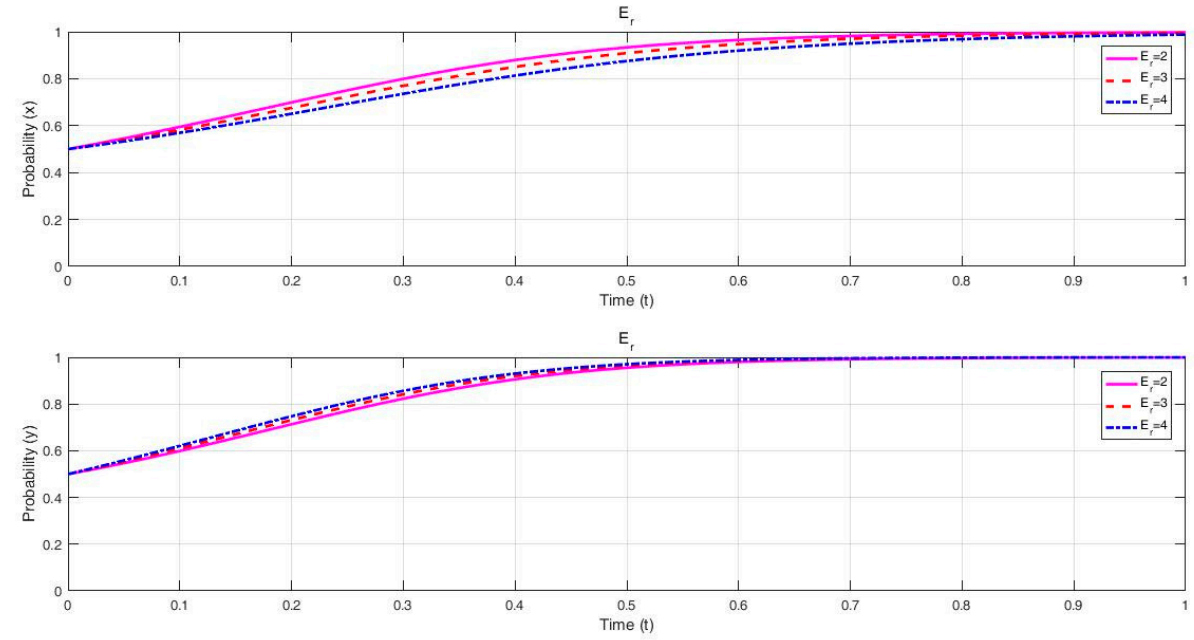

Figure 5. The impact of $E_{r}$ on the game. 

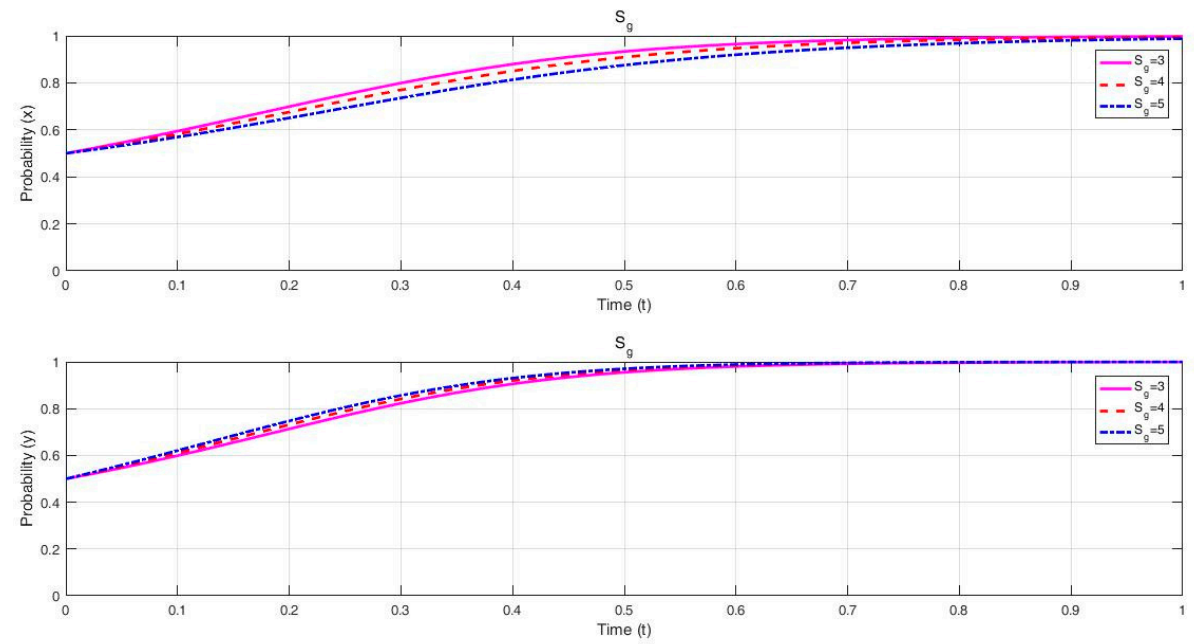

Figure 6. The impact of $S_{g}$ on the game.

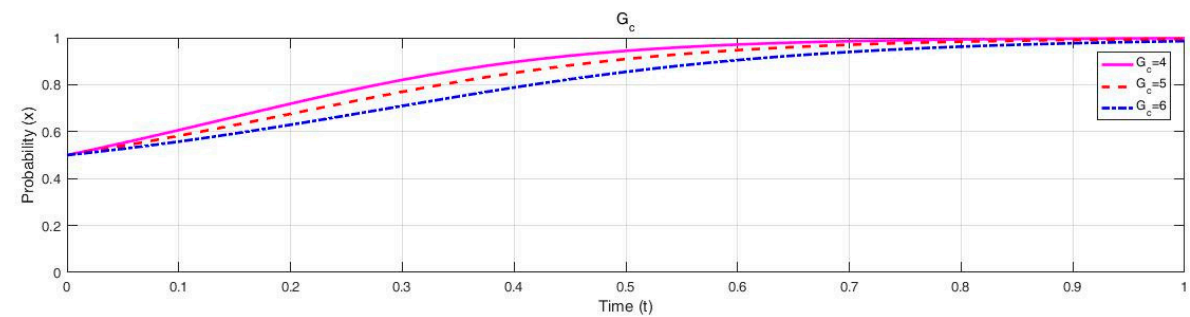

$G_{0}$

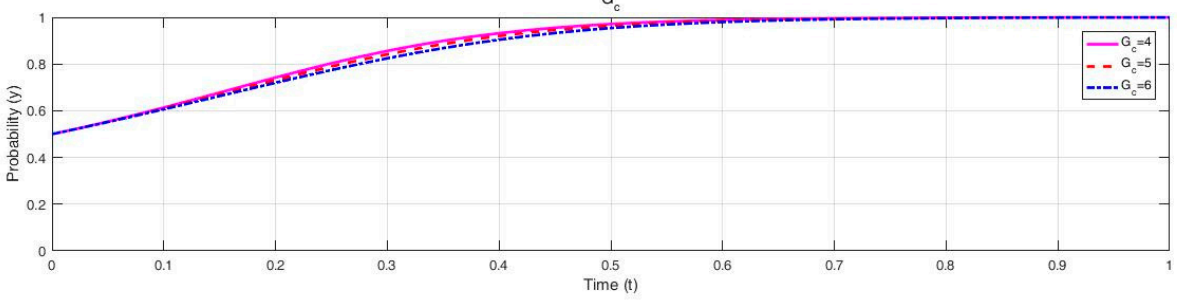

Figure 7. The impact of $G_{C}$ on the game.
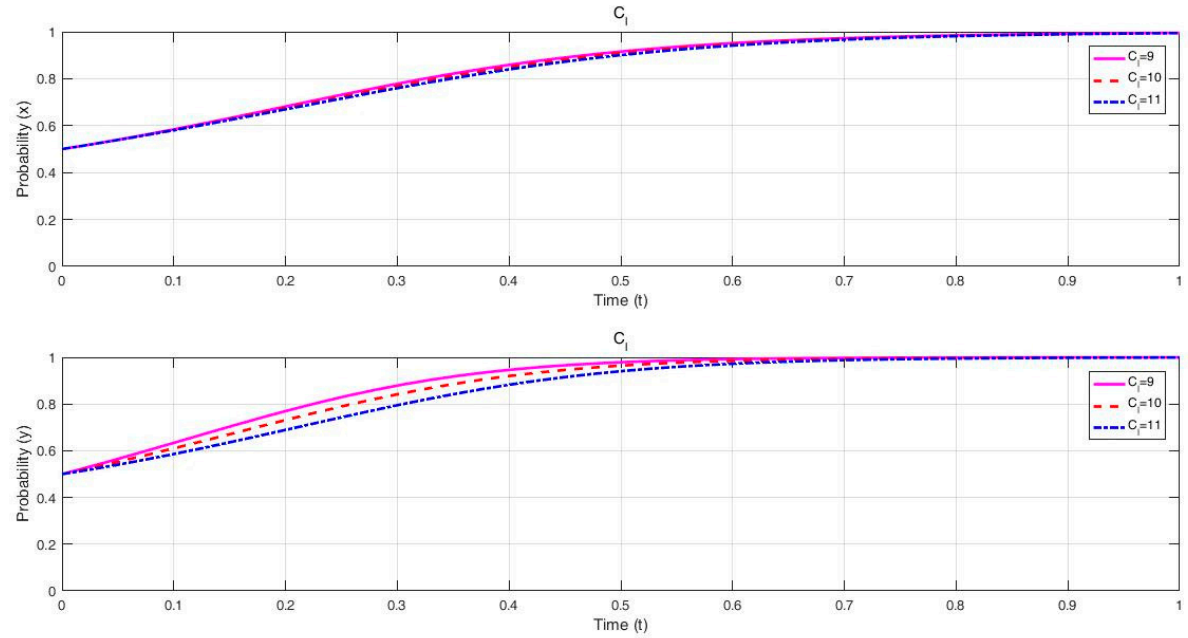

Figure 8. The impact of $C_{l}$ on the game. 


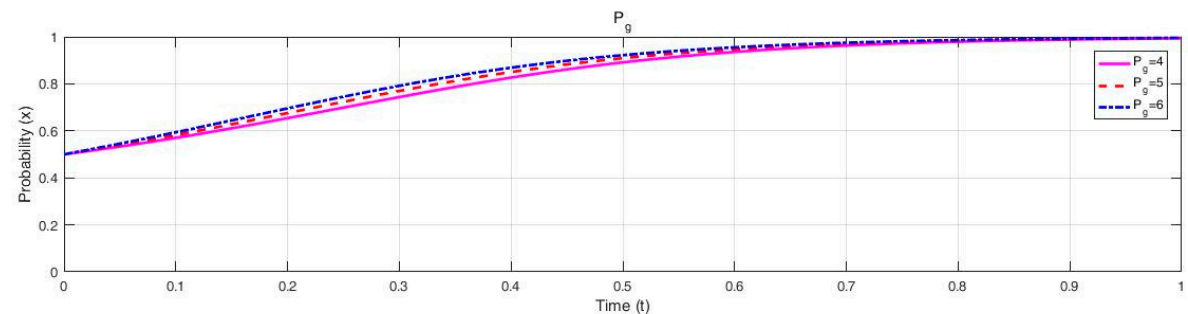

$\mathrm{P}_{9}$

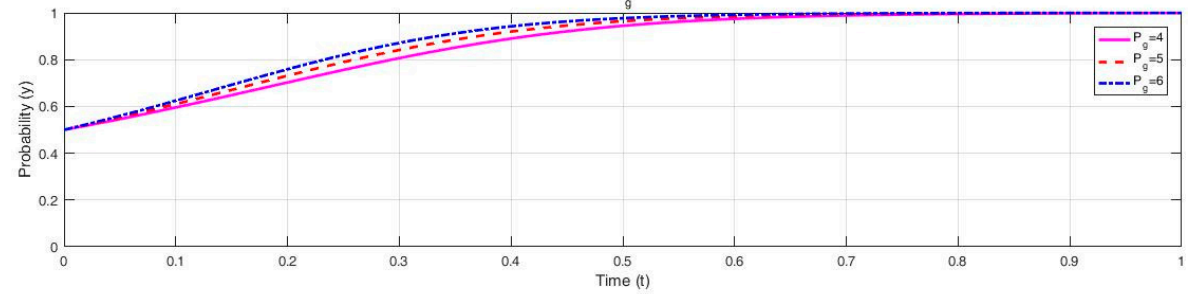

Figure 9. The impact of $P_{g}$ on the game.
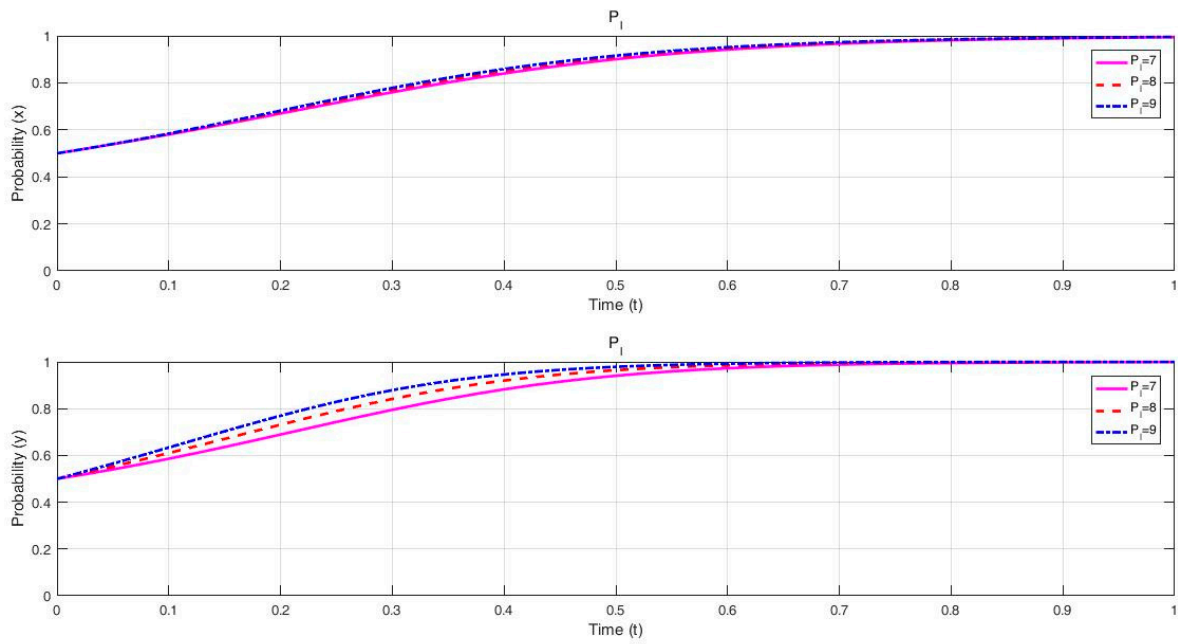

Figure 10. The impact of $P_{l}$ on the game.

\section{Discussion}

Equation (15) provides the policy design for how to set the values of key parameters in the game model to promote the active reaction to the CBAM of both actors. From the first equation in Equation (15), we see that with the government actively responding to carbon tariffs, low-carbon production by export companies should bring more benefits to the government than the total cost borne by the government. Considering that it is necessary to maintain financial incentives including subsidies and export rebates to encourage export companies to conduct low-carbon production which is consistent with Reference [35], the focus is on the extent to which the governmental expenditure of active reaction to the CBAM should decrease and political benefits due to the active reaction to the CBAM should increase. This is consistent with Reference [56]. From the second equation in Equation (15), we see that the sum of the benefits for the government plus extra low-carbon benefits for export companies is greater than the sum of reactive costs for both government and export companies. Therefore, from the perspective of the government, in addition to the increase in political benefits due to the active reaction to the CBAM and decrease in the expenditure of active reaction to the CBAM, the government should advance the penalty level for export companies that do not actively respond to the CBAM and stick to high-carbon production. This is consistent with Reference [64]. From the perspective of export companies, technological progress should be improved to reduce the extra cost by purchasing low-carbon technologies and equipment. This is inconsistent with Reference [55], which argues that "Climate cooperation remains a challenge, and 
this challenge may become even bigger if low-carbon technologies are available at lower costs, due to a stronger free-rider incentive". Furthermore, profit because of low-carbon production should increase by incorporating export companies into the national carbon market as quickly as possible. This is consistent with Reference [40]. From the third equation in Equation (15), we see that the additional cost of choosing low-carbon production for export companies is less than the sum of the additional low-carbon benefits they receive plus governmental subsidies, export tax rebates, and penalties. This is the precondition for the export companies' participation in this game. If the additional cost of choosing low-carbon production for export companies is greater than the sum of the low-carbon benefits plus subsidies, export rebates, and penalties, export companies would not have the strategy choice of low-carbon production. If these three conditions are met, the entire game system will stabilize at $D(1,1)$. This setting of parameter values is the policy design mechanism that promotes the active participation of the two actors in the context of the CBAM. This design is analogous to Reference [58] which answers the research question "What is the CBAM value that maximizes total welfare?".

From Figure 4, we see that increases in $G_{r}$ can make both actors evolve to one more quickly. Thus, it is useful to increase the political benefits of the government when choosing to respond to the CBAM actively. From Figures 5 and 6, we see that an increase in $E_{r}$ and $S_{g}$ can make the government evolve to one more slowly but makes export companies evolve to one more quickly. Thus, there is the option wherein if the decision-makers want to make the government react to the CBAM more quickly, they will choose to decrease the financial incentives to export companies, and if they want to make export companies react to the CBAM more quickly, they will choose to increase the financial incentives. However, as long as the values meet the requirements of Equation (15), the two actors will both finally evolve to the ideal state. From Figures 7 and 8 we see that a decrease in $G_{c}$ and $C_{l}$ can make both actors evolve to one more quickly. This means it is beneficial to reduce the cost of active reaction to the CBAM for both actors. From Figures 9 and 10, we see that an increase in $P_{g}$ and $P_{l}$ can make both actors evolve to one more quickly. This means that decision-makers should strengthen the penalty for high-carbon-export companies and increase the profits for low-carbon-export companies.

\section{Conclusions}

The objective of this study was to investigate how the government and export companies of non-EU countries, such as China, respond to the potential impact of the carbon tariff. Although the final implementation and specific rules of the CBAM are still uncertain, green international trade barriers could become a long-term threat. Therefore, the non-EU countries should take precautions and prepare for possible carbon tariffs by improving domestic carbon market mechanisms and by encouraging low-carbon development. This study analyzed how the CBAM affects China and relevant export companies. We found that the government and export companies are two salient actors in the context of the forthcoming CBAM. Both of them can choose whether to respond to the CBAM actively or passively. Based on their potential strategy choice, we set various parameters used in the methodology. We investigated their interactive nexus using the evolutionary game coupled with replicator equations in order to obtain the ideal evolutionary stable strategy. As a result, a policy design for how to set the values of key parameters in the model that can promote the two actors' positive reaction to the CBAM is created. Based on the sensitivity analyses of key parameters, we found that in order to promote the social low-carbon progress, it is helpful to increase profits and to reduce cost for two actors when they choose to positively react. In sum, we provide a new insight into the effect of the CBAM on the export countries from a dynamic game perspective compared with the existing literature. According to the results, we propose some recommendations. This paper is expected to provide insights for other countries analogous to China in the context of carbon tariffs.

At the governmental level, the government should perfect the carbon market. The first step is to introduce more practical rules and regulations. The second is to expand 
the scope of participants and to lower the threshold to enter the carbon market. The third is to include products that may be covered by the CBAM in the carbon market and to promote the integration of the domestic carbon market with the international carbon market to obtain tariff exemptions. While advancing the carbon market, carbon tax should be introduced in due course. Carbon taxes and a carbon market can complement each other. Carbon taxes not only can increase the motivation for companies to reduce emissions but also can provide these companies with exemptions from carbon tariffs. Furthermore, the government's revenue from the carbon tax can be used to promote low-carbon development. In addition, the government should promote the transformation of the economy and export structure and reduce dependence on exports.

At the enterprise level, by guiding enterprises to accelerate the low-carbon transformation, they can realize the trend of green trade in the future and avoid being taxed on the export of products. First, companies should deepen their understanding of productive carbon footprints and reduce carbon emissions in the process of production. Second, export companies should strengthen technological innovation and research on carbon capture usage and storage (CCUS). Companies can also counteract their own carbon emissions by purchasing forestry carbon sink projects, photovoltaic power generation projects, wind power projects, etc.

At the EU level, as China is the largest trading partner of the EU, the EU should actively engage in bilateral dialogues with China, overcome policy and technological gaps, and properly resolve trade barriers. In 2020, China and the EU established a highlevel dialogue on the environment and climate, aiming to increase China-EU cooperation in the green field. In addition to a normalized dialogue between high-level executives, various national departments, universities, companies, and other government and private institutions should also be encouraged to establish a carbon dialogue mechanism with the EU to deepen mutual understanding and to increase political benefits for the government. It can also cooperate with the EU to strengthen the calculation of embodied carbon in Chinese trade products to reduce the relevant cost for the government. Furthermore, the EU can give preference to Chinese export companies that actively implement low-carbon production to increase their low-carbon profit.

Although this paper demonstrates original findings, the limitation of the study still remains. The implementation of the CBAM involves many stakeholders including EU countries, non-EU countries, importers, and exporters. In this work, we concentrated on studying the nexus between two actors, that is non-EU countries and exporters. However, other actors can be included in the present model to construct a multi-player game to make a more comprehensive and systematic analysis. This issue needs to be explored in a future study.

Author Contributions: Conceptualization, T.H. and T.Z.; methodology, T.Z.; software, T.Z.; validation, T.H., Z.L. and T.Z.; formal analysis, T.Z.; investigation, T.Z.; resources, Z.L.; data curation, T.H.; writing—original draft preparation, T.H.; writing—review and editing, T.Z.; visualization, T.Z.; supervision, Z.L.; project administration, T.Z.; funding acquisition, Z.L. All authors have read and agreed to the published version of the manuscript.

Funding: This research received no external funding.

Institutional Review Board Statement: Not applicable.

Informed Consent Statement: Not applicable.

Data Availability Statement: Not applicable.

Acknowledgments: The authors thank the editors and the anonymous reviewers for their helpful and constructive comments and suggestions on the drafts of this paper.

Conflicts of Interest: The authors declare no conflict of interest. 


\section{References}

1. Carbon Border Adjustment Mechanism. Available online: https://ec.europa.eu/taxation_customs/green-taxation-0/carbonborder-adjustment-mechanism_en (accessed on 25 December 2021).

2. Cheng, H. Border carbon adjustments with endogenous assembly locations. Econ. Model. 2021, 105, 105666. [CrossRef]

3. A WTO-Compatible EU Carbon Border Adjustment Mechanism. Available online: https: / / www.europarl.europa.eu/doceo/ document/TA-9-2021-0071_EN.html (accessed on 25 December 2021).

4. Fragkos, P.; Fragkiadakis, K.; Paroussos, L. Reducing the Decarbonisation Cost Burden for EU Energy-Intensive Industries. Energies 2021, 14, 236. [CrossRef]

5. Hancock, L.; Wollersheim, L. EU Carbon Diplomacy: Assessing Hydrogen Security and Policy Impact in Australia and Germany. Energies 2021, 14, 8103. [CrossRef]

6. Lim, B.; Hong, K.; Yoon, J.; Chang, J.-I.; Cheong, I. Pitfalls of the EU's Carbon Border Adjustment Mechanism. Energies 2021, 14, 7303. [CrossRef]

7. Joint Statement Issued at the Conclusion of the 30th BASIC Ministerial Meeting on Climate Change hosted by India on 8th April 2021 I South African Government. Available online: https:/ / www.gov.za/nr/speeches/joint-statement-issued-conclusion-30thbasic-ministerial-meeting-climate-change-hosted (accessed on 25 December 2021).

8. A European Union Carbon Border Adjustment Mechanism: Implications for Developing Countries | UNCTAD. Available online: https://unctad.org/webflyer/european-union-carbon-border-adjustment-mechanism-implications-developing-countries (accessed on 30 November 2021).

9. Tagliapietra, S.; Wolff, G.B. Conditions are ideal for a new climate club. Energy Policy 2021, 158, 112527. [CrossRef]

10. Nogrady, B. China launches world's largest carbon market: But is it ambitious enough? Nature 2021, 595, 637. [CrossRef]

11. Koester, S.; Hart, D.M.; Sly, G. Unworkable Solution: Carbon Border Adjustment Mechanisms and Global Climate Innovation; Information Technology and Innovation Foundation: Washington, DC, USA, 2021.

12. Hecht, M.; Peters, W. Border adjustments supplementing a cap and trade system to combat climate change. Clim. Chang. Econ. 2019, 10, 1950017. [CrossRef]

13. Hecht, M.; Peters, W. Border Adjustments Supplementing Nationally Determined Carbon Pricing. Environ. Resour. Econ. 2019, 73, 93-109. [CrossRef]

14. Liu, C.; Huang, W.L.; Yang, C. The evolutionary dynamics of China's electric vehicle industry-Taxes vs.subsidies. Comput. Ind. Eng. 2017, 113, 103-122. [CrossRef]

15. Chen, W.T.; Hu, Z.H. Using evolutionary game theory to study governments and manufacturers' behavioral strategies under various carbon taxes and subsidies. J. Clean. Prod. 2018, 201, 123-141. [CrossRef]

16. Fang, Y.; Chen, L.; Mei, S.; Wei, W.; Huang, S.; Liu, F. Coal or electricity? An evolutionary game approach to investigate fuel choices of urban heat supply systems. Energy 2019, 181, 107-122. [CrossRef]

17. Wang, Q.; Tan, Z.; De, G.; Pu, L.; Wu, J. Research on promotion incentive policy and mechanism simulation model of energy storage technology. Energy Sci. Eng. 2019, 7, 3147-3159. [CrossRef]

18. Gao, L.; Zhao, Z.-Y. The Evolutionary Game of Stakeholders' Coordination Mechanism of New Energy Power Construction PPP Project: A China Case. Sustainability 2020, 12, 1045. [CrossRef]

19. Zhang, K.; Liang, Q.-M. Recent progress of cooperation on climate mitigation: A bibliometric analysis. J. Clean. Prod. 2020, 277, 123495. [CrossRef]

20. Zhang, Z. The US proposed carbon tariffs and China's responses. Energy Policy 2010, 38, 2168-2170. [CrossRef]

21. Lin, B.; Li, A. Impacts of carbon motivated border tax adjustments on competitiveness across regions in China. Energy 2011, 36, 5111-5118. [CrossRef]

22. Li, A.; Zhang, A. Will carbon motivated border tax adjustments function as a threat? Energy Policy 2012, 47, 81-90. [CrossRef]

23. Li, A.; Zhang, A.; Cai, H.; Li, X.; Peng, S. How large are the impacts of carbon-motivated border tax adjustments on China and how to mitigate them? Energy Policy 2013, 63, 927-934. [CrossRef]

24. Cosbey, A.; Droege, S.; Fischer, C.; Munnings, C. Developing Guidance for Implementing Border Carbon Adjustments: Lessons, Cautions, and Research Needs from the Literature. Rev. Environ. Econ. Policy 2019, 13, 3-22. [CrossRef]

25. Yu, B.; Zhao, Q.; Wei, Y.-M. Review of carbon leakage under regionally differentiated climate policies. Sci. Total Environ. 2021, 782, 146765. [CrossRef]

26. Xu, Q.; Hobbs, B.F. Economic efficiency of alternative border carbon adjustment schemes: A case study of California Carbon Pricing and the Western North American power market. Energy Policy 2021, 156, 112463. [CrossRef]

27. Caron, J. Estimating carbon leakage and the efficiency of border adjustments in general equilibrium-Does sectoral aggregation matter? Energy Econ. 2012, 34, S111-S126. [CrossRef]

28. Bednar-Friedl, B.; Schinko, T.; Steininger, K.W. The relevance of process emissions for carbon leakage: A comparison of unilateral climate policy options with and without border carbon adjustment. Energy Econ. 2012, 34, S168-S180. [CrossRef]

29. Böhringer, C.; Balistreri, E.J.; Rutherford, T.F. The role of border carbon adjustment in unilateral climate policy: Overview of an Energy Modeling Forum study (EMF 29). Energy Econ. 2012, 34, S97-S110. [CrossRef]

30. Burniaux, J.-M.; Chateau, J.; Duval, R. Is there a case for carbon-based border tax adjustment? An applied general equilibrium analysis. Appl. Econ. 2013, 45, 2231-2240. [CrossRef] 
31. Rocchi, P.; Serrano, M.; Roca, J.; Arto, I. Border Carbon Adjustments Based on Avoided Emissions: Addressing the Challenge of Its Design. Ecol. Econ. 2018, 145, 126-136. [CrossRef]

32. Droege, S. Using border measures to address carbon flows. Clim. Policy 2011, 11, 1191-1201. [CrossRef]

33. Zhang, K.U.N.; Liang, Q.-M.; Liu, L.-J.; Xue, M.-M.; Yu, B.-Y.; Wang, C.E.; Han, R.; Du, Y.-F.; Yao, Y.-F.; Chang, J.-J.; et al. Impacts of mechanisms to promote participation in climate mitigation: Border carbon adjustments versus uniform tariff measures. Clim. Chang. Econ. 2020, 11, 2041007. [CrossRef]

34. Dissou, Y.; Eyland, T. Carbon control policies, competitiveness, and border tax adjustments. Energy Econ. 2011, 33, 556-564. [CrossRef]

35. Mörsdorf, G. A simple fix for carbon leakage? Assessing the environmental effectiveness of the EU carbon border adjustment. Energy Policy 2021, 112596. [CrossRef]

36. Jakob, M. Why carbon leakage matters and what can be done against it. One Earth 2021, 4, 609-614. [CrossRef]

37. Gerbeti, A. Market Mechanisms for Reducing Emissions and the Introduction of a Flexible Consumption Tax. Glob. J. Flex. Syst. Manag. 2021, 22, 161-178. [CrossRef]

38. Thube, S.; Peterson, S.; Nachtigall, D.; Ellis, J. The economic and environment benefits from international co-ordination on carbon pricing: A review of economic modelling studies. Environ. Res. Lett. 2021, 16, 113002. [CrossRef]

39. Fischer, C.; Fox, A.K. Comparing policies to combat emissions leakage: Border carbon adjustments versus rebates. J. Environ. Econ. Manag. 2012, 64, 199-216. [CrossRef]

40. Acar, S.; Aşıcı, A.A.; Yeldan, A.E. Potential effects of the EU's carbon border adjustment mechanism on the Turkish economy. Environ. Dev. Sustain. 2021. [CrossRef]

41. Winchester, N.; Paltsev, S.; Reilly, J.M. Will Border Carbon Adjustments Work? B. E. J. Econom. Anal. Policy 2011, 11. [CrossRef]

42. Bao, Q.; Tang, L.; Zhang, Z.; Wang, S. Impacts of border carbon adjustments on China's sectoral emissions: Simulations with a dynamic computable general equilibrium model. China Econ. Rev. 2013, 24, 77-94. [CrossRef]

43. Kuik, O.; Hofkes, M. Border adjustment for European emissions trading: Competitiveness and carbon leakage. Energy Policy 2010, 38, 1741-1748. [CrossRef]

44. Holmes, P.; Reilly, T.; Rollo, J. Border carbon adjustments and the potential for protectionism. Clim. Policy 2011, 11, 883-900. [CrossRef]

45. Sakai, M.; Barrett, J. Border carbon adjustments: Addressing emissions embodied in trade. Energy Policy 2016, 92, 102-110. [CrossRef]

46. Schinko, T.; Bednar-Friedl, B.; Steininger, K.W.; Grossmann, W.D. Switching to carbon-free production processes: Implications for carbon leakage and border carbon adjustment. Energy Policy 2014, 67, 818-831. [CrossRef]

47. Weitzel, M.; Hübler, M.; Peterson, S. Fair, optimal or detrimental? Environmental vs. strategic use of border carbon adjustment. Energy Econ. 2012, 34, S198-S207. [CrossRef]

48. Banks, G.D.; Fitzgerald, T. A sectoral approach allows an artful merger of climate and trade policy. Clim. Change 2020, 162, 165-173. [CrossRef]

49. Eicke, L.; Weko, S.; Apergi, M.; Marian, A. Pulling up the carbon ladder? Decarbonization, dependence, and third-country risks from the European carbon border adjustment mechanism. Energy Res. Soc. Sci. 2021, 80, 102240. [CrossRef]

50. Sanctuary, M. Border carbon adjustments and unilateral incentives to regulate the climate. Rev. Int. Econ. 2018, 26, 826-851. [CrossRef]

51. Branger, F.; Quirion, P. Would border carbon adjustments prevent carbon leakage and heavy industry competitiveness losses? Insights from a meta-analysis of recent economic studies. Ecol. Econ. 2014, 99, 29-39. [CrossRef]

52. Allevi, E.; Oggioni, G.; Riccardi, R.; Rocco, M. Evaluating the carbon leakage effect on cement sector under different climate policies. J. Clean. Prod. 2017, 163, 320-337. [CrossRef]

53. Mehling, M.A.; van Asselt, H.; Das, K.; Droege, S.; Verkuijl, C. Designing Border Carbon Adjustments for Enhanced Climate Action. Am. J. Int. Law 2019, 113, 433-481. [CrossRef]

54. Monjon, S.; Quirion, P. A border adjustment for the EU ETS: Reconciling WTO rules and capacity to tackle carbon leakage. Clim. Policy 2011, 11, 1212-1225. [CrossRef]

55. Helm, C.; Schmidt, R.C. Climate cooperation with technology investments and border carbon adjustment. Eur. Econ. Rev. 2015, 75, 112-130. [CrossRef]

56. Anouliès, L. The Strategic and Effective Dimensions of the Border Tax Adjustment. J. Public Econ. Theory 2015, 17, 824-847. [CrossRef]

57. Irfanoglu, Z.B.; Sesmero, J.P.; Golub, A. Potential of border tax adjustments to deter free riding in international climate agreements Environ. Res. Lett. 2015, 10, 24009. [CrossRef]

58. Eyland, T.; Zaccour, G. Carbon tariffs and cooperative outcomes. Energy Policy 2014, 65, 718-728. [CrossRef]

59. Alboszta, J.; Mie,kisz, J. Stability of evolutionarily stable strategies in discrete replicator dynamics with time delay. J. Theor. Biol. 2004, 231, 175-179. [CrossRef]

60. Xiao, T.; Yu, G. Supply chain disruption management and evolutionarily stable strategies of retailers in the quantity-setting duopoly situation with homogeneous goods. Eur. J. Oper. Res. 2006, 173, 648-668. [CrossRef]

61. Wu, B.; Liu, P.F.; Xu, X.F. An evolutionary analysis of low-carbon strategies based on the government-enterprise game in the complex network context. J. Clean. Prod. 2017, 141, 168-179. [CrossRef] 
62. Fan, R.G.; Dong, L.L.; Yang, W.G.; Sun, J.Q. Study on the optimal supervision strategy of government low-carbon subsidy and the corresponding efficiency and stability in the small-world network context. J. Clean. Prod. 2017, 168, 536-550. [CrossRef]

63. Mahmoudi, R.; Rasti-Barzoki, M. Sustainable supply chains under government intervention with a real-world case study: An evolutionary game theoretic approach. Comput. Ind. Eng. 2018, 116, 130-143. [CrossRef]

64. Long, R.; Yang, J.; Chen, H.; Li, Q.; Fang, W.; Wang, L. Co-evolutionary simulation study of multiple stakeholders in the take-out waste recycling industry chain. J. Environ. Manag. 2019, 231, 701-713. [CrossRef]

65. Qiao, W.; Yin, X. Understanding the impact on energy transition of consumer behavior and enterprise decisions through evolutionary game analysis. Sustain. Prod. Consum. 2021, 28, 231-240. [CrossRef]

66. 'CBAM' Carbon Levy Will Only Hit a Fraction of Chinese Exports to EU. Available online: https://chinadialogue.net/en/ climate/cbam-carbon-levy-will-only-hit-a-fraction-of-chinese-exports-to-eu/ (accessed on 1 December 2021).

67. Zhao, R.; Zhou, X.; Han, J.J.; Liu, C.L. For the sustainable performance of the carbon reduction labeling policies under an evolutionary game simulation. Technol. Forecast. Soc. Change 2016, 112, 262-274. [CrossRef]

68. Tang, S.; Zhou, W.; Li, X.; Chen, Y.; Zhang, Q.; Zhang, X. Subsidy strategy for distributed photovoltaics: A combined view of cost change and economic development. Energy Econ. 2021, 97, 105087. [CrossRef]

69. An, H.; Yang, R.; Ma, X.; Zhang, S.; Islam, S.M.N. An evolutionary game theory model for the inter-relationships between financial regulation and financial innovation. N. Am. J. Econ. Financ. 2021, 55, 101341. [CrossRef]

70. Taylor, P.D.; Jonker, L.B. Evolutionary stable strategies and game dynamics. Math. Biosci. 1978, 40, 145-156. [CrossRef]

71. Encarnação, S.; Santos, F.P.; Santos, F.C.; Blass, V.; Pacheco, J.M.; Portugali, J. Paths to the adoption of electric vehicles: An evolutionary game theoretical approach. Transp. Res. Part B Methodol. 2018, 113, 24-33. [CrossRef]

72. Smith, J.M.; Price, G.R. The Logic of Animal Conflict. Nature 1973, 246, 15-18. [CrossRef]

73. Shan, H.Y.; Yang, J.L. Sustainability of photovoltaic poverty alleviation in China: An evolutionary game between stakeholders. Energy 2019, 181, 264-280. [CrossRef]

74. Friedman, D. Evolutionary Games in Economics. Econometrica 1991, 59, 637-666. [CrossRef]

75. Zhang, H.M.; Xu, Z.D.; Zhou, D.Q.; Cao, J. Waste cooking oil-to-energy under incomplete information: Identifying policy options through an evolutionary game. Appl. Energy 2017, 185, 547-555. [CrossRef]

76. Zhao, X.; Ren, L.; Zhang, Y.; Wan, G. Evolutionary game analysis on the behavior strategies of power producers in renewable portfolio standard. Energy 2018, 162, 505-516. [CrossRef] 